\title{
Feuerbach: da crítica da religião à defesa da dignidade humana
}

\section{Feuerbach: from criticism of religion to the defense of human dignity}

\author{
Arlei de Espíndola ${ }^{1}$
}

\begin{abstract}
Resumo
$\mathrm{O}$ artigo tenta problematizar a tendência (existente ainda hoje) de julgar-se Feuerbach um autor menor, que serviria de ponto de passagem entre Hegel e Marx. Salienta que o filósofo alemão precisa ser lido antes com a pretensão compreensiva, e não de forma negativa e crítica. Só assim é possível identificar o caráter humanista de sua reflexão e reconhecer que seu propósito consiste em salvaguardar a religião em sua essencialidade humana.
\end{abstract}

Palavras-chaves: Filosofia da religião. Materialismo sensitivo. Natureza humana. Ética. Liberdade.

\begin{abstract}
The article aims at discussing the current trend of considering Feuerbach a minor author, which would place him as a crossing point between Hegel and Marx. It points out that the German philosopher needs to be read with the intent to comprehend first rather than through a negative and critical perspective. Only then it is possible to identify the humanistic aspects of his thinking and acknowledge that his purpose consists in safeguarding religion in its human essence.
\end{abstract}

Keywords: Philosophy of religion. Sensitive materialism. Human nature. Ethics. Freedom.

\section{Introdução}

Com suas ideias pouco convencionais acerca de assuntos religiosos, disseminadas em todos seus escritos, Ludwig Feuerbach (1804-1872) motivou o surgimento de leituras críticas, e mesmo até apressadas, em torno de sua obra, movidas por uma gama considerável de preconceitos. Dessa prática resultou, desde o século XIX, uma espécie de atenuação e recusa do sentido rico e do caráter profundo que sua filosofia carrega em seu arcabouço teórico-reflexivo. Se nos debruçarmos sobre seus textos, e acompanharmos com atenção suas articulações filosóficas, tenderemos, no entanto, a notar que ele é um filósofo muito lúcido e atento a todo o debate que se desenrola em sua época, mantendo ciência a respeito da complexidade dos problemas que visa a enfrentar.

Colocado neste clima intelectual desfavorável, por força daquela precipitação e equívoco acima referido, o filósofo só é visto como ponto de passagem, como mero intermediário, entre os gigantes intelectuais Hegel e Marx. Mas Friedrich Engels admitiu em 1886 que seu Feuerbach e o fim da filosofia clássica alemã representava uma grande oportunidade para render homenagem ao filósofo de Landshut. Essa homenagem, aliás, lhe

\footnotetext{
${ }_{1}$ Doutor em Filosofia pela Universidade Estadual de Campinas/UNICAMP. Professor da Graduação e do Programa de Mestrado em Filosofia da Universidade Estadual de Londrina/UEL
} 
era devido realizar - em nome dele e de Marx -, se desenvolvesse a crítica solicitada do livro de Starcke sobre sua reflexão filosófica. Era correto e justo no entendimento do parceiro intelectual de Marx "reconhecer plenamente a influência que Feuerbach, mais que nenhum outro filósofo pós-hegeliano, exercera sobre nós durante nosso período de embate e luta." (ENGELS, 2011).

Apesar de colocar-se dessa forma no escrito que esboçara já na década de 40, Engels contribuiu para fortalecer a ideia de que Feuerbach significava um simples elo de uma corrente que contava com Hegel e Marx nas duas extremidades. Isso apareceu confirmado claramente com suas palavras do texto antes referido, no qual comunica já não ter-se prendido, juntamente com Marx, aos escritos e à obra do autor em pauta, senão nessa ocasião, que surgira como uma singular oportunidade. Nesse momento, Engels assevera: "Feuerbach [...] em certos aspectos representa um elo intermédio entre a filosofia hegeliana e nossa concepção.” (ENGELS, 2011).

Com esse conceito de uma gama grande de seus opositores, ao criticar os fundamentos da religião e as bases do idealismo hegeliano, o que Feuerbach consegue empreender por meio de seus escritos, em seu estágio de maior maturidade intelectual, é apenas preparar o terreno para o materialismo histórico de Marx, sem avançar um passo além disso.

Feuerbach, em Berlim, estudou filosofia, após ter cursado teologia em Heidelberg, e foi aluno de Hegel por dois anos, e desde logo assumiu a postura de um hegeliano convicto. Pelo menos em quatro de seus principais escritos, conforme o testemunho de Henri Arvon, publicados entre 1830 e 1838, aparece impregnado o espírito hegeliano que ele cultivava com ardor. ${ }^{2}$
Mas com o tempo, na medida em que se deram seus avanços teóricos, por força de seus estudos continuados, Hegel se tornou menos representativo, e Feuerbach acabou fazendo-se um combatente enérgico de seu idealismo. Isso permitiu a Engels afirmar conclusivamente: "a trajetória de Feuerbach é de um hegeliano - não inteiramente ortodoxo, é verdade - que marcha para o materialismo. Trajetória que, ao chegar a uma determinada fase, implica numa (sic) ruptura total com o sistema idealista de seu predecessor." (ENGELS, 1977, p. 91-92).

Mesmo que Engels faça essas afirmações em relação a Feuerbach, ele pensa que o filósofo não consegue, na verdade, superar sua vinculação e subordinação ao pensamento de Hegel, e, assim, deixa cair por terra o que haveria de revolucionário em sua doutrina: "como é possível, no entanto, que o gigantesco impulso dado por Feuerbach resultasse tão estéril nele próprio? Simplesmente porque Feuerbach não consegue encontrar a saída do reino das abstrações, imortalmente odiado por ele próprio, para a realidade viva"(ENGELS, 1977, p. 102).

Marx sentiu-se atraído, por seu turno, pelo materialismo e pelo sensualismo feuerbachiano desde quando iniciou seu combate às ideias de Hegel em 1843, com seu livro Crítica da filosofia do direito de Hegel. E é fato que o pensamento de Feuerbach, importante na formação de seu cabedal teórico, significa um desafio para os estudiosos de sua filosofia até hoje, e é pouco conhecido, aliás, de nossa intelectualidade e pouco visitado ainda em nosso ambiente acadêmico. Conforme Sampaio e Frederico (2006, p. 7):

[...] a influência de Feuerbach foi decisiva na formação do pensamento de Marx [...]. Presença marcante (em suas) obras juvenis [...], o crítico da alienação religiosa é ainda pouco conhecido do público brasileiro.

2 Conforme Henri Arvon (1964), os livros seriam os seguintes: Pensamentos sobre morte e imortalidade (1830); História da filosofia moderna desde Bacon de Verulâmio até Benedito de Spinoza (1833); Crítica do Anti-Hegel (1835); Pierre Bayle, uma contribuição à história da filosofia e da humanidade (1838). 
Apontado quase sempre como o "responsável" pela "conversão" de Marx ao materialismo ou, contrariamente, como o ideólogo humanista que manteve o jovem Marx atrelado a uma problemática não-científica (Althusser), Feuerbach continua sendo um desafio para os estudiosos de Marx.

Com efeito, ao se reduzir Feuerbach ao posto de simples mediador das orientações filosóficas idealistas e materialistas, triunfantes, respectivamente, pelas mãos, de Hegel e Marx, muito se contribui para o fortalecimento da noção de que Feuerbach seria um autor menor, sem grande brilho e expressividade teórica. No entanto, Henri Arvon destaca a importância de não se cometer esse equívoco, se conservamos o interesse de analisar seriamente e compreender o sentido do ideário filosófico do pensador com o propósito de saber de fato sobre sua real importância no quadro da história da filosofia:

[...] se portanto se quer render justiça a Feuerbach, convém liberá-lo, ao menos no que concerne a certos aspectos de seu pensamento, dos liames marxistas que o sufocam, a fim de lhe restituir essa relativa independência que ele está no direito de reclamar, tanto com relação a Marx que o sucede, como diante de Hegel, que o precede (ARVON, 1964, p. 19).

Esse comentador francês, importante na disseminação, em seus primórdios, da meditação feuerbachiana nesse ambiente cultural, entende que os equívocos, geradores de uma compreensão precipitada e produtores de confusão, só podem ser desfeitos se houver o esforço de ler-se efetivamente o filósofo, acompanhando os passos progressivos de sua reflexão, que se faz mesmo acurada e propositiva. Portanto: "para que o pensamento feuerbachiano recobre seu ordenamento verdadeiro, antes que recorrer aos críticos de Marx, tratemos de acompanhá-lo em seus esforços múltiplos em vista de assegurar à filosofia de seu tempo um novo ponto de partida." (ARVON, 1964, p. 20).

Cabe levar em conta os elementos originais, e todos aqueles aspectos profundos veiculados pela especulação de Feuerbach em torno da problemática religiosa, aspectos que, muitas vezes, são deixados à sombra por entender-se erradamente que ele é um pensador menor. Por isso, vale dizer que o filósofo alemão possui um nível grande de conhecimentos sólidos, de caráter profundo, marcados por uma notável erudição.

Não vamos considerar, pelo menos neste artigo, o reflexo e a ressonância viva que se nota, nos textos de Feuerbach, das várias fontes de leitura que ele coleciona. Dentre elas merecem ser destacadas, por exemplo, filósofos chaves no debate estabelecido no interior da tradição iluminista francesa. Mas podemos garantir que não foi só Marx que se beneficiou com seu legado teórico ao valorizar sua crítica da alienação religiosa. Evidenciamos também o impacto que suas ideias produzem, notadamente, sobre Nietzsche e Freud, malgrado a possibilidade de se recortar expressivas diferenças. Vale mencionar, ainda, a título ilustrativo, o peso da reflexão do filósofo de Landshut acerca da filosofia dialógica de Martin Buber.

Ludwig Feuerbach direcionou a maior parte de sua atenção, e mobilizou grande parte de seu interesse intelectual, para estudar o problema de Deus e a questão de natureza religiosa, tratando de enfocá-los sob a perspectiva própria da filosofia. Eleger prioritariamente esse objeto como alvo maior de preocupação, em seus esforços teóricos, não significou para Feuerbach, porém, desconhecer que "religião" e "política" são coisas relacionadas, formando uma sólida unidade. Suas Preleções sobre a essência da religião, de 1848, deixam claro que ele admite a presença inexorável do nexo entre esses dois valiosos elementos culturais: "a religião, objeto dessas preleções, está intimamente ligada à política." (FEUERBACH, 1989, p. 11).

Nessa etapa de sua empreitada intelectual, ciente da referida ligação, Feuerbach revela-se incomodado tanto com o idealismo filosófico quanto com o idealismo político. Assumido o compromisso de falar para um público de estudantes universitários a respeito de "religião", ele quer imprimir ao seu discurso um caráter eminentemente político. 
Interessam-lhe, nessa ocasião, as coisas vistas pelo seu lado prático. E seguindo em seu esforço reflexivo o propósito de tocar na temática específica da essência da religião, o filósofo procura ter esse fenômeno pela perspectiva materialista que a ele imprime em toda sua trajetória e toda sua produção filosófica e especulativa. Segundo Feuerbach (1989, p. 11): [...] já de há muito nos ocupamos e satisfazemos bastante com o discurso e a escrita; exigimos que finalmente a palavra se torne carne, e o espírito, matéria; estamos fartos tanto do idealismo filosófico quanto do político; agora queremos nos tornar materialistas políticos. ${ }^{3}$

Feuerbach desfrutou de uma breve carreira enquanto professor universitário, em Erlangen, onde ministrou aulas de história da filosofia, lógica e metafísica, momento no qual já pôde manifestar sua contrariedade face aos filósofos tradicionais. Assim revelou a identificação embrionária que conservava com a ala dos hegelianos de esquerda, e manteve o anseio de trabalhar com um novo conceito de filosofia, imprimindo a essa matéria um sentido prático. A esse respeito, Adriana Serrão (1991, p. x) comenta:

[...] a filosofia é encarada sobretudo como tarefa prática que deve aliar a livre expressão das ideias a uma intenção salvífica. As sucessivas intervenções nos grandes debates contemporâneos - que se concentravam em torno das relações entre filosofia, cristianismo e política -, [...] aproximavam Feuerbach de algumas orientações partilhadas pelo movimento Jovem Hegeliano.

A carreira de Feuerbach como professor universitário foi interrompida logo no começo da experiência, e isso se deveu, em grande medida, ao lançamento anônimo, em 1830, de um de seus primeiros escritos, ao qual intitulou Pensamentos sobre a morte e a imortalidade. Estiveram em suas ideias religiosas, e anticristãs, aí veiculadas, a responsabilidade maior por tal consequência negativa de efeito irreversível.

Essas ideias possuíam o poder semelhante ao fogo, isto é, a força viva de acarretarem queimaduras. E esse resultado tornado efetivo estimularia e justificaria a ação contestatória, então, de seus leitores mais talentosos ou impertinentes. Estes se assumiriam como adversários, e viriam a contribuir para que ele acabasse abandonado e caísse no ostracismo intelectual pelo resto de sua vida. Em suma, de acordo com Rubem Alves, que pensa certamente para além da escrita do livro de Feuerbach publicado em 1830, aqueles que leram sua vasta produção teórica: "foram queimados, e por isso ele sofreu a punição do exílio intelectual pelo resto de sua vida" (ALVES, 1989, p. 7). ${ }^{4}$

O eixo central, o núcleo maior, da pesquisa filosófica de Feuerbach aparece, em especial, em A essência do cristanismo, seu livro de maior expressão, que gerou grande impacto, no campo especulativo, quando lançado em Leipzig em 1841. Nele, encontramos o filósofo defendendo que os mistérios de Deus e da religião se resolvem no campo da antropologia. Temos um desdobramento dessa tese, propugnada por Feuerbach, no curso de sua terceira preleção, no momento em que se refere às obras onde haverá de se ocupar de sua doutrina ou filosofia. Aí ele indica que o centro de sua reflexão reside na ideia de a teologia não passar de antropologia, e de o homem ser o fundamento da religião, por isso tem grande valor buscar efetivamente conhecê-lo:

[...] esta minha doutrina é simplesmente: teologia é antropologia, ou seja, no objeto da religião a que chamamos Theós em grego, Gott em alemão, expressase nada mais do que a essência do homem, ou: o deus do homem não é nada mais que a essência divinizada

\footnotetext{
3 Conforme Friedrich Engels: “[...] a política era nessa época matéria muito espinhosa; daí porque a luta principal fosse dirigida contra a religião; essa luta, contudo, era também indiretamente uma luta política, particularmente depois de 1840" (ENGELS, 1977, v. 1, p. 86).

4 Segundo Rubem Alves: "ribeiro de fogo: esta é a tradução literal do nome Feuerbach. E nele o nome corresponde aos fatos: não é possível atravessá-lo sem se queimar” (ALVES, 1989, p. 7).
} 
do homem, portanto a história da religião ou, o que dá na mesma, de Deus (porque quão diversas as religiões tão diversos os deuses, e as religiões tão diversas quão diversos são os homens) nada mais é do que a história do homem (FEUERBACH, 1989, p. 23).

Diante dessa compreensão, tratar de Deus e conhecer os enigmas próprios da religião, requer que se tenha disposição, em verdade, para estudar a natureza mais profunda e substantiva do ser humano. Alcançar saberes acerca do fundamento deste último, em torno da origem deste, ao sentido de seu ser e de sua existência, confunde-se, portanto, com um saber atinente à própria divindade.

Tomado e movido pela sinceridade própria do espírito protestante, Feuerbach, sem pretender estar em conivência com esse credo, afirma o que pensa e lança as bases mais sólidas do ateísmo, pondo em dúvida a existência da figura do Deus transcendente. Sua fala termina por ter um impacto maior no meio intelectual onde está inserido, pois ele não é um locutor qualquer. Seu elo com a religião e a teologia, seu vínculo com o espírito protestante, o fazem figurar como um de dentro da fé que se expressa, sendo ali exercitada.

Feuerbach, operando pelo dito latino homo homini Deus, reconhece o ser absoluto no próprio homem, entendendo que este último projeta seu "eu ideal" na figura suprema de Deus; daí acaba por resultar a religião como uma espécie de espelho do ser humano. Ora, suas palavras, ao denunciarem haver problemas na perspectiva da tradição e delinearem uma convicção ateia, só poderiam gerar malestar, acarretando sua retirada da cena intelectual oficial, reinante. Rubem Alves, observando esse fragmento de sua teoria, indica que:

[...] o fogo do pensamento de Feuerbach [...] está na sua afirmação de que todo o nosso pensamento sobre Deus é pensamento sobre nós mesmos. A religião é o espelho dos homens. Muitos já haviam dito a mesma coisa mas o seu fogo não queimava, porque estavam de fora. Mas Feuerbach estava dentro e botou fogo na própria casa. Não é de espantar, portanto, que tenha sido expulso (ALVES, 1989, p. 8).
Como desdobramento do mesmo eixo central da pesquisa de Feuerbach, encontramos sua referência aos ganhos que almeja ver alcançado pelo homem com sua crítica à religião. Por esse último, quer ver recobrado o estado de dignidade que vivia antes de se fazer um ser alienado e joguete de uma cultura de certa forma inautêntica. A fantasia, o engano produzido pela religião apresentar-se-ia como uma forma de alienação, por projetar os conceitos do ideal humano num ser supremo. Entretanto, ela, finalmente, chamou a atenção de um leitor atento como Marx, que reconheceu o mérito de sua teoria. Essa teoria foi descrita de maneira exemplar, recorrendo-se às expressões históricas da religião. Com isso, verificou-se como se estabelecia a alienação com a sobreposição do culto e da devoção à Deus. Segundo Celso Frederico (2009, p. 25):

O elemento central do pensamento feuerbachiano que Marx, como leitor "tendencioso", por sua conta e risco, procurou apoderar-se para criticar a filosofia do Direito de Hegel é a teoria da alienação. Aqui reside o cerne não só da contestação lançada à dialética hegeliana como também da crítica implacável à ilusão religiosa que conduziu Marx ao materialismo.

Dentro da perspectiva humanista que Feuerbach constrói, ganha a cena a antropologia, neutralizando o império dos impulsos teológicos. Com essa dimensão do saber assentada agora em primeiro plano, o homem torna-se responsável pelos frutos da cultura em geral, e torna-se consciente de si e esclarecido quanto ao fundamento das coisas. Com isso, ele não precisa violentar-se, promover idolatrias, e renunciar a si próprio, e ao Deus que existe dentro de si mesmo. Conforme Erich Fromm (1983, p. 51):

[...] quanto mais o homem transfere seus próprios poderes para os ídolos, tanto mais pobre ele fica e tanto mais dependente dos ídolos, pois estes só lhe permitem reaver pequena parte do que era originalmente dele [...]. A idolatria é sempre a adoração de algo em que o homem colocou suas próprias forças criadoras e a que agora se submete, em vez de experienciar-se a si próprio em seu ato criador. 
Abandonando as construções pessoais míticas e enganadoras próprias da consciência religiosa, o ser humano alcança o entendimento sobre seu valor e seu poder na ordem da natureza. Assim, ele neutraliza o pendor de construir ídolos, e de promover idolatrias, e faz-se, ao final, um Deus para si mesmo.

\section{Referências}

ALVES, R. Apresentação. In: FEUERBACH, L. Preleções sobre a essência da religião. Campinas: Papirus, 1989.

ARVON, H.Feuerbach: sa vie, son oeuvre, sa philosophie. Paris: Presses Universitaires de France, 1964.

ENGELS, F. Ludwig Feuerbach e o fim da filosofia clássica alemã. In: MARX, K.; ENGELS, F. Textos. São Paulo: Edições Sociais, 1977. v. 1.

. Ludwig Feuerbach y el fin de la filosofia clásica alemana. Disponível em: <http://www.marxists.org/ espanol $/ \mathrm{m}$-e $/ 1880 \mathrm{~s} /$ feuer/index.htm $>$. Acesso em: 3 mar. 2011.

FEUERBACH, L. Preleções sobre a essência da religião. Campinas: Papirus, 1989.

FREDERICO, C. O jovem Marx: 1843-1844 as origens da ontologia do ser social. 2. ed. São Paulo: Expressão Popular, 2009.

FROMM, E. Conceito marxista de homem. 8. ed. Rio de Janeiro: Zahar, 1983.

SAMPAIO, B. A.; FREDERICO, C. Dialética $e$ materialismo: Marx entre Hegel e Feuerbach. Rio de Janeiro: UFRJ, 2006.

SERRÃO, Adriana Veríssimo. Apresentação. FEUERBACH, L. A essência do cristianismo. 2. ed. Lisboa: Fundação Calouste Gulbenkian, 1991. 